\title{
The Asymmetric Effect of Bitcoin on Altcoins: Evidence from the Nonlinear Autoregressive Distributed Lag (NARDL) Model
}

\begin{abstract}
This paper examines the asymmetric effect of Bitcoin on three altcoins, namely Ethereum (ETH), Ripple (XRP) and Litecoin (LTC) by using the Nonlinear Autoregressive Distributed Lag (NARDL) model for the period July 2015 to March 2019. We provide evidence on the asymmetric impact of Bitcoin on altcoins both in the short-run and in the long-run. In the shortrun, a decrease in Bitcoin price has greater effect than an increase on the prices of altcoins. This asymmetry is more frequent after the 2017 cryptocurrency price crash.

Keywords: Bitcoin, Cryptocurrency, Asymmetry, Ethereum, Ripple, Litecoin, NARDL JEL Classification: C32, G15, E42, G12, C12
\end{abstract}




\section{Introduction}

Bitcoin was introduced by Nakamoto (2008) as a digital currency and open-source online payment system. Especially with its highly volatile price and future prospect, it attracts the attention of investors, regulatory bodies, and media. Following Bitcoin, around 2,000 cryptocurrencies have been released and most of them are traded in international markets (Ballis and Drakos, 2019). However, Bitcoin has a dominant role in the market with a share around $65 \%$ in market capitalization by May, 2020.

The literature on financial aspects of the cryptocurrency market has recently emerged and is developing rapidly. For instance, several studies explore the relationship between investors' attention and Bitcoin prices (Urquhart, 2018; Dastgir et al. 2018), the existence of bubbles in the cryptocurrency market (Cheah and Fry, 2015; Corbet et al. 2018), the efficiency of cryptocurrencies (Urquhart, 2016; Sensoy, 2019), hedging capabilities of cryptocurrencies against other assets (Bouri et al. 2017; Poyser, 2019) and against uncertainty (Demir et al. 2018; Gozgor et al. 2019).

Another strand of this literature examines the interrelationship between Bitcoin and other cryptocurrencies. By using Autoregressive Distributed Lag Model, Ciaian et al. (2018) show that Bitcoin and altcoin markets are interdependent, being such relationship significantly stronger in the short-run than in the long-run. 15 out of 16 altcoins are affected from shocks to Bitcoin in the short-run, while only four altcoins are cointegrated with Bitcoin prices in the long-run. Corbet et al. (2018) find that Bitcoin prices affect Ripple and Litecoin while these cryptocurrencies have limited effect on Bitcoin, given that Bitcoin is the clear leader in the cryptocurrency market. In terms of volatility spillovers, Bitcoin has less effect on other cryptocurrencies while Litecoin's volatility shocks have significant effects on Bitcoin and 
Ripple. Ji et al. (2019) emphasize the important role of Bitcoin and Litecoin as they take place in the center of the return and volatility connectedness networks. This implies that volatility and return shocks of Bitcoin and Litecoin have significant effects on other cryptocurrencies. According to Katsiampa (2019a), there are interdependencies between Ether and Bitcoin and conditional volatility and correlation of those two cryptocurrencies are sensitive to major news. In a similar vein, Sifat et al. (2019) show that there is a bi-directional causality between Bitcoin and Ethereum by using hourly and daily data. By using data for five major cryptocurrencies, Katsiampa (2019b) shows that there are significant interdependencies. For Bitcoin, Ether, Ripple, and Litecoin (except Stellar Lumen), conditional volatility can capture asymmetric effects between good and bad news. Katsiampa et al. (2019) document a bi-directional shock transmission between Bitcoin and both Litecoin and Ether. On the other hand, according to Zięba et al. (2019), Bitcoin prices do not affect and are not affected from other cryptocurrencies while there are interdependencies between cryptocurrencies except Bitcoin. On the contrary, Yaya et al. (2019) show that there are cointegration relationships between Bitcoin and altcoins which weakens in the post-crash period. Yi et al. (2019) mention that volatility connectedness among eight cryptocurrencies changes in time and rises when there is uncertainty. A further analysis of 52 cryptocurrencies show that they are interconnected and cryptocurrencies with higher market caps are more likely to generate volatility shocks to others.

Previous literature provides mixed results on the relationship between Bitcoin and other cryptocurrencies. This paper examines the asymmetric effects of Bitcoin (BTC) on altcoins, namely Ethereum (ETH), Ripple (XRP) and Litecoin (LTC), by using the Non-linear Autoregressive Distributed Lag (NARDL) approach. Bitcoin is expected to affect altcoins, as Bitcoin is the dominant cryptocurrency in terms of market capitalization and public interest. Compared to other cryptocurrencies, Bitcoin is more likely to serve as the preferred medium of 
exchange due to its usage for a wider range of goods and services. Likewise, Bitcoin is preferred for investment purposes. Moreover, for initial coin offerings (ICO) and altcoin sales transactions, investors are likely to use Bitcoin (Ciaian et al. 2018). To our knowledge, this is the first paper presenting evidence on the asymmetric effects of Bitcoin to altcoins. We provide evidence on the asymmetric impact of Bitcoin on altcoins both in the short-run and in the longrun. In the short-run, a decrease in Bitcoin price has greater impact than an increase on the price of altcoins. The asymmetry is more frequent after the December 2017 cryptocurrency price crash.

The rest of the paper is structured as follows. Section 2 presents the data and methodology. Findings are given in Section 3 and last section concludes the paper.

\section{Empirical design}

\subsection{Data}

Daily price data are used for Bitcoin and top three altcoins, namely Ethereum (ETH), Ripple (XRP) and Litecoin (LTC) ${ }^{1}$, which have been obtained from www.coinmarketcap.com. We follow the model of Ciaian et al. (2018) and introduce several control variables to the estimations. Wikipedia visits for each altcoin per day $^{2}$ are included to control for the virtual media attention-driven demand. Oil price, gold price, 10-year treasure maturity rate, USD/EUR parity, and Nasdaq Composite Index are also comprised in the model to account for global macroeconomic and financial developments. The data period used is July 2015 - March $2019^{3}$. Table 1 presents the descriptive statistics of the variables.

\footnotetext{
${ }^{1}$ Those altcoins are listed in top three after Bitcoin at www.coinmarketcap.com

${ }^{2}$ obtained from https://tools.wmflabs.org/pageviews

${ }^{3}$ Starting period of the data is related with the data availability of Wikipedia visits.
} 


\section{$<$ Table $1>$}

\subsection{Methodology}

The literature uses the Non-linear Autoregressive Distributed Lag (NARDL) approach to examine the asymmetric effects of exchange rates to exports (Verheyen, 2013), uncertainty to gold prices (Bilgin et al. 2018), exchange rates to investments (Bahmani-Oskooee et al. 2018) and uncertainty to money demand (Bahmani-Oskooee and Nayeri, 2018). In terms of cryptocurrencies, Bouri et al. (2018) examine the asymmetric relationship between stock price, gold price, bond price, commodity prices, and US dollar index. The NARDL approach is useful to study asymmetric impact in the long-run and in the short-run by modeling asymmetric cointegration. Moreover, the joint analysis of nonlinearity and non-stationarity can be done through an unrestricted error correction model. In this regard, Bitcoin return series is decomposed into partial sum of positive (negative) decompositions as it is suggested by Shin et al. (2014) as the following:

$B T C_{t}^{+}=\sum_{j=1}^{t} \Delta B T C_{t}^{+}=\sum_{j=1}^{t} \max \left(\Delta B T C_{t}, 0\right), B T C_{t}^{-}=\sum_{j=1}^{t} \Delta B T C_{t}^{-}=\sum_{j=1}^{t} \min \left(\Delta B T C_{t}, 0\right)$

where BTC denotes Bitcoin prices. The asymmetric error correction model (AECM) is as follows: 


$$
\begin{aligned}
& \Delta A L T_{t}=\alpha+\alpha_{1} A L T_{t-1}+\beta_{1} B T C_{t-1}{ }^{+}+\beta_{2} B T C_{t-1}{ }^{-}+\beta_{3} G O L D_{t-1}+\beta_{4} N A S D A Q_{t-1} \\
& +\beta_{5} O I L_{t-1}+\beta_{6} T E N Y R_{t-1}+\beta_{7} W I K I_{t-1}+\sum_{i=0}^{j} \gamma_{1} \Delta G O L D_{t-i} \\
& +\sum_{i=0}^{k} \gamma_{2} \Delta N A S D A Q_{t-i}+\sum_{i=0}^{m} \gamma_{3} \Delta O I L_{t-i}+\sum_{i=0}^{n} \gamma_{4} \Delta T E N Y R_{t-i} \\
& +\sum_{i=0}^{p} \gamma_{5} \Delta W I K I_{t-i}+\sum_{i=1}^{r} \gamma_{6} \Delta A L T_{t-i}+\sum_{i=0}^{z}\left(\delta_{i}{ }^{+} \Delta B T C^{+}{ }_{t-i}+\delta_{i}{ }^{-} \Delta B T C_{t-i}{ }^{-}\right) \\
& +\mu_{t}
\end{aligned}
$$

where ALT stands for altcoin prices, GOLD for gold prices, NASDAQ for Nasdaq Composite Index, OIL for oil prices, TENYR for 10-yr treasury maturity rate and WIKI for daily Wikipedia search number for each cryptocurrency. All variables are in daily logarithmic level series following Bouri et al. (2018).

If $\delta_{i}^{+}=\delta_{i}^{-}$for all $\mathrm{i}=0, . ., \mathrm{z}$ then it can be said that the effect is symmetric in the short-run. By following the same logic, if $\beta_{1}=\beta_{2}$ then we cannot reject symmetry condition in the long-run. In order to observe cointegration, we use NARDL bounds test approach, which is developed by Shin et al. (2014). The main advantage of this approach is that, it is applicable even if the variables are $\mathrm{I}(0), \mathrm{I}(1)$ or mutually cointegrated. Moreover, the series need not to be integrated in the same order to find a cointegrating relationship. The only limitation is, the variables should be integrated at most of order one.

By performing Augmented Dickey Fuller tests, we check whether all our variables are eligible to be present in our model. The test results indicate that except daily Wikipedia visits, which is $\mathrm{I}(1)$, all explanatory variables in our model are $\mathrm{I}(0) .{ }^{4}$ Therefore, the specification for NARDL

\footnotetext{
${ }^{4} \mathrm{We}$ did not report the results to save space, but they can be provided upon request.
} 
approach is met. In this methodology, we use BDM t-statistic (tBDM) (Banerjee et al., 1998) and PSS F-statistic (FPSS) test (Pesaran et al, 2001) to detect cointegration. In this regard, the null hypothesis (no cointegration) against the alternative hypothesis (cointegration) is tested. The hypotheses for the FPSS can be shown as,

$$
H_{0}: \alpha_{1}=\beta_{1}=\beta_{2}=\beta_{3}=\beta_{4}=\beta_{5}=\beta_{6}=\beta_{7}=0
$$

against the alternative that $H_{0}$ is not true. There are two critical values for these tests. If the value obtained from the test result is greater than the upper bound, we can conclude that there is cointegration. On the contrary, if the test statistic is less than the lower bound or it falls between the boundaries, then there is no evidence of a long-run relationship.

Yaya et al. (2019) show that the strength of relationships between Bitcoin and altcoins change after the market crash in December 2017. In order to capture the effect of cryptocurrency price crash on asymmetric relationship, we divide the sample into two as pre-crash (before December 2017) and post-crash (after December 2017) periods as it is suggested by Yaya et al. (2019).

\section{Findings}

Results of the bounds cointegration test are reported in Table 2. The results obtained from FPSS and $\mathrm{T}_{\mathrm{BDM}}$ tests verify that there exists a long-run relationship between altcoin price and their explanatory variables for all altcoins. After fulfilling the cointegration specification, we continue with the estimated short-run and long-run coefficients which are presented in Table 3. In our analysis, we use AIC (Akaike Information Criteria) to determine optimal lag length.

We begin our analysis with full sample results. In all established models, it can be observed that Bitcoin has a statistically significant and positive effect in the short-run. Meaning that, an 
increase in Bitcoin price drives all three altcoins' prices up and vice versa. However, it is also shown that increases and decreases in the Bitcoin price have different effects on altcoins. In order to test the presence of an asymmetric effect of Bitcoin on altcoins in the short-run, we follow "additive short-run symmetry condition" which is proposed by Shin et al. (2009). This proposition states that the symmetry condition can only be rejected if the sum of decreases are significantly different from the sum of increases. Consequently, we construct our Wald-test based on this proposition and reject the null hypothesis at 5\% and conclude that the impact of a decrease in Bitcoin price on altcoins is greater than the impact of an increase. This implies that altcoins are more sensitive to decreases than to increases in Bitcoin prices.

For the case of long-run, we only observe asymmetry for the case of Ripple. The coefficient of Bitcoin is negative and the impact of a decrease is again higher than the impact of an increase. For Litecoin and Ethereum, Bitcoin price is not significant and consequently we do not observe any asymmetry.

\section{$<$ Table 2>}

<Table 3>

We also examine whether great crash in cryptocurrency market (Yaya et al. 2019) occurred in December 2017 changes the structure of relationship between Bitcoin and altcoins. The findings indicate that the asymmetric behavior is more frequent in post-crash period. We do observe asymmetric effect of Bitcoin price on all altcoins in post-crash period. For the case of shortrun, the asymmetric pattern that is observed for full sample applies. The impact of a decrease in Bitcoin price dominates the case for an increase for all altcoins. Taking long-run results into consideration, we only observe an asymmetry in Litecoin equation. Unlike previous cases, here, 
the impact of an increase in Bitcoin dominates the one for a decrease. For Ethereum and Ripple, the symmetry condition cannot be rejected based on Wald-test. For post-crash period, it is also worthy to note that Bitcoin has a positive coefficient for all altcoins in the long-run, being different from the observation that we have for full sample in Ripple. When pre-crash period is taken into account, it can be said that the only asymmetry is in Litecoin equation. Both for the long-run and the-short run, the negative effect of Bitcoin is greater for the case of Litecoin.

Through nine models that we establish, seven of them indicate an asymmetric impact of Bitcoin on altcoins in the short-run, while it is just three for the long-run. According to this result, it can be said that the asymmetric behavior of Bitcoin on altcoins is mainly concentrated in the shortrun. Apart from that, the negative impact of Bitcoin surpasses the positive one almost in all cases. On this basis, we imply that the negative effect of Bitcoin dominating the positive effect is more frequent. Lastly, we indicate that the asymmetry is more frequent in the post-crash period in the short-run. This finding is in line with the current literature, as Yaya et al. (2019) also observe a change in the dynamics between Bitcoin and altcoins in terms of volatility and shock persistence when pre-crash and post-crash periods are compared.

\section{Conclusion}

This paper examines the asymmetric impact of Bitcoin on altcoins. By using a Non-linear Autoregressive Distributed Lag (NARDL) approach, our findings suggest that Bitcoin price affects prices of altcoins asymmetrically in the short-run for all altcoins. Specifically, a decrease in Bitcoin price has a greater impact on altcoins compared to an increase. This finding provides an insight for the investors in altcoins. As we previously discussed, Bitcoin is the main cryptocurrency and the leader of the market. In this regard, the investors of altcoins should consider to re-design their portfolios as we provide evidence of a non-linear relationship 
between Bitcoin and altcoins. We also analyze the impact of the December 2017 great crash on the asymmetric behavior and show that the main source of asymmetry in full sample is originated from the post-crash period in the short-run. Further research can examine the asymmetric effect in bull and bear market periods.

\section{REFERENCES}

Bahmani-Oskooee, M., Halicioglu, F. and Neumann, R., 2018. Domestic investment responses to changes in the real exchange rate: A symmetries of appreciation versus depreciation. International Journal of Finance \& Economics, 23(4), pp.362-375.

Bahmani-Oskooee, M. and Nayeri, M.M., 2018. Policy Uncertainty and the demand for money in Australia: An asymmetry analysis. Australian Economic Papers, 57(4), pp.456-469.

Ballis, A. and Drakos, K., 2019. Testing for Herding in the Cryptocurrency Market. Finance Research Letters.

Banerjee, A., Dolado, J., \& Mestre, R. (1998). Error-correction mechanism tests for cointegration in a single-equation framework. Journal of time series analysis, 19(3), 267-283.

Bilgin, M.H., Gozgor, G., Lau, C.K.M. and Sheng, X., 2018. The effects of uncertainty measures on the price of gold. International Review of Financial Analysis, 58, pp.1-7.

Bouri, E., Molnár, P., Azzi, G., Roubaud, D. and Hagfors, L.I., 2017. On the hedge and safe haven properties of Bitcoin: Is it really more than a diversifier?. Finance Research Letters, 20, pp.192-198.

Bouri, E., R. Gupta, A. K. Tiwari, and D. Roubaud (2017). Does bitcoin hedge global uncertainty? evidence from wavelet-based quantile-in-quantile regressions. Finance Research Letters 23, 87-95. 
Cheah, E.T. and Fry, J., 2015. Speculative bubbles in Bitcoin markets? An empirical investigation into the fundamental value of Bitcoin. Economics Letters, 130, pp.32-36.

Ciaian, P. and Rajcaniova, M., 2018. Virtual relationships: Short-and long-run evidence from BitCoin and altcoin markets. Journal of International Financial Markets, Institutions and Money, 52, pp.173-195.

Corbet, S., Lucey, B. and Yarovaya, L., 2018. Datestamping the Bitcoin and Ethereum bubbles. Finance Research Letters, 26, pp.81-88.

Corbet, S., Meegan, A., Larkin, C., Lucey, B. and Yarovaya, L., 2018. Exploring the dynamic relationships between cryptocurrencies and other financial assets. Economics Letters, 165, pp.28-34.

Dastgir, S., Demir, E., Downing, G., Gozgor, G. and Lau, C.K.M., 2019. The causal relationship between Bitcoin attention and Bitcoin returns: Evidence from the Copula-based Granger causality test. Finance Research Letters, 28, pp.160-164.

Demir, E., Gozgor, G., Lau, C.K.M. and Vigne, S.A., 2018. Does economic policy uncertainty predict the Bitcoin returns? An empirical investigation. Finance Research Letters, 26, pp.145-149.

Gozgor, G., Tiwari, A.K., Demir, E. and Akron, S., 2019. The relationship between Bitcoin priceand trade policy uncertainty. Finance Research Letters, 29, pp.75-82.

Ji, Q., Bouri, E., Lau, C.K.M. and Roubaud, D., 2019. Dynamic connectedness and integration in cryptocurrency markets. International Review of Financial Analysis, 63, pp.257272.

Katsiampa, P., 2019a. Volatility co-movement between Bitcoin and Ether. Finance Research Letters. Forthcoming

Katsiampa, P., 2019b. An empirical investigation of volatility dynamics in the cryptocurrency market. Research in International Business and Finance. Forthcoming 
Katsiampa, P., Corbet, S. and Lucey, B., 2019. Volatility spillover effects in leading cryptocurrencies: A BEKK-MGARCH analysis. Finance Research Letters, 29, pp.68-74.

Nakamoto S., 2008, Bitcoin: a peer-to-peer electronic cash system Available at:https://bitcoin.org/bitcoin.pdf.

Poyser, O., 2019. Exploring the dynamics of Bitcoin's price: a Bayesian structural time series approach. Eurasian Economic Review, 9(1), pp.29-60.

Sensoy, A., 2019. The inefficiency of Bitcoin revisited: A high-frequency analysis with alternative currencies. Finance Research Letters, 28, pp.68-73.

Sifat, I.M., Mohamad, A. and Shariff, M.S.B.M., 2019. Lead-Lag Relationship between Bitcoin and Ethereum: Evidence from Hourly and Daily Data. Research in International Business and Finance. Forthcoming.

Shin, Y., Yu, B. and Greenwood-Nimmo, M., 2014. Modelling asymmetric cointegration and dynamic multipliers in a nonlinear ARDL framework. In William C. Horrace and Robin C. Sickles (Eds.), Festschrift in Honor of Peter Schmidt: Econometric Methods and Applications. New York: Springer, 281-314.

Urquhart, A., 2018. What causes the attention of Bitcoin?. Economics Letters, 166, pp.40-44.

Urquhart, A., 2016. The inefficiency of Bitcoin. Economics Letters, 148, pp.80-82.

Verheyen, F., 2013. Exchange rate nonlinearities in EMU exports to the US. Economic Modelling, 32, pp.66-76.

Yaya, O.S., Ogbonna, A.E. and Olubusoye, O.E., 2019. How persistent and dynamic inter-dependent are pricing of Bitcoin to other cryptocurrencies before and after 2017/18 crash?. Physica A: Statistical Mechanics and its Applications, forthcoming 
Yi, S., Xu, Z. and Wang, G.J., 2018. Volatility connectedness in the cryptocurrency market: Is Bitcoin a dominant cryptocurrency?. International Review of Financial Analysis, 60, pp.98-114.

Zięba, D., Kokoszczyński, R. and Śledziewska, K., 2019. Shock transmission in the cryptocurrency market. Is Bitcoin the most influential?. International Review of Financial Analysis, 64, pp.102-125. 